\title{
Obituary
}

\section{Obituary for Professor Sir Martin Roth, FRS}

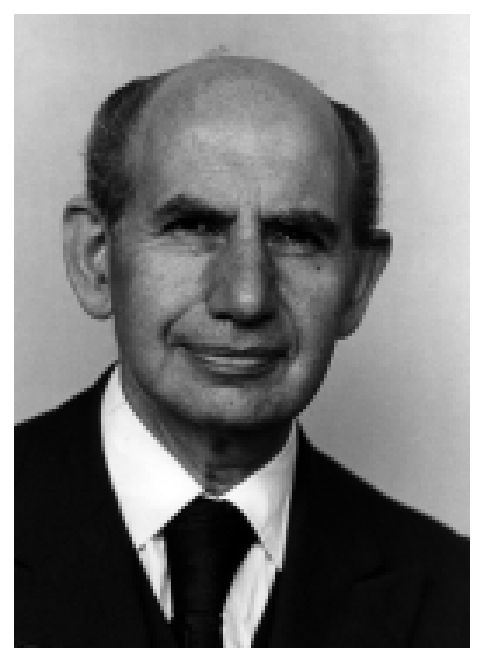

His colleagues mourn the passing of Sir Martin Roth, who from modest origins became the leading figure in British psychiatry of his day, one of only three psychiatrists ever awarded a Fellowship of the Royal Society, along with Sigmund Freud. He was the first President of the Royal College of Psychiatrists and played a critical role in the foundation of the College. But he will be remembered best as the teacher of a generation of psychiatrists and as an inspiration for research in mental illness. He will be remembered among neuropathologists particularly for his delineation of the correlation between dementia of the Alzheimer type and the lesions that Alzheimer discovered.

Sir Martin was born on 6 November 1917 in Budapest and moved with his family to the East End of London as a young boy. He studied medicine at St. Mary's Hospital and first trained in neurology under Lord Brain. Brain communicated not only an interest in neurology, but also in the psychological aspects of illness, psychoanalysis and philosophy, which stimulated Sir Martin to enter psychiatry. He went on to train in psychiatry at the Maudsley Hospital with influences particularly from Aubrey Lewis, Eliot Slater and
Erich Guttman. He then moved to the Crichton Royal Hospital in Dumfries where he worked with Willy Mayer-Gross.

It was from the triad of Mayer-Gross, Slater and Roth that emerged the classic textbook, "Clinical Psychiatry", which became the bedrock of Sir Martin's influence on British psychiatry. The first edition appeared in 1954 and it continued with new editions and revisions until 1977. This textbook set a stamp on British psychiatry well into the 1980's in defining what it is to be a psychiatrist, and what the business of psychiatry is as a medical discipline. It was written with immense erudition and humanity, with lucid clinical descriptions directly linked to the rich phenomenology of the German literature, and an underlying hunger to achieve a coherent scientific understanding of the nature of mental illness.

His textbook was a sure, humane and safe pilot for the discipline of psychiatry in ideologically stormy times: the transition from the post-Freudian thinking to the age of Prozac. These were times that Sir Martin and his coauthors inspired with a unique blend of clarity, critical thought, breadth of scholarship, charm, and humanity. It was in the German tradition of Emile Kraepelin, who in his day transformed psychiatry with his clear descriptions of the major psychiatric syndromes, only to be swept aside in late life by the rise of the Freudians.

Freud, as Sir Martin liked to say, was not a psychiatrist, but a neurologist. Freud has come to be loved more in departments of literature and the history of ideas than in departments of psychiatry. This is because he never really came to grips professionally with the stuff of mental illness. The times of vast psychiatric institutions housing populations in excess of 1,000 souls in varying degrees of torment and hopelessness are still etched in the collective social consciousness, and their residue lives on in the stigma which is still too often attached to mental illness. 
The transition came in 1952 with Delay and Deniker's first description in Paris of the remarkable calming influence of chlorpromazine, a drug developed originally as a pre-operative sedative, in a series of 38 psychotic patients. This was the time of the first introduction of antidepressants that worked, initially the monoamine oxidase inhibitors, and then the tricyclics, dangerous drugs in overdose, but highly effective clinically. Although newer drugs with safer profiles have been developed since, the therapeutic landscape has not altered in its fundamentals now for 50 years. It fell to Sir Martin to teach his generation what these developments meant for understanding the discipline of psychiatry.

The recognition came that mental illness cannot be, of its essence, a moral disorder of the psyche that originates from adverse formative experiences, but consists in highly stereotyped expressions of characteristic states of the brain. These can be identified diagnostically and can be modified chemically. Now the mainstream, in Sir Martin's day this was a major battlefield from which he eventually emerged as the victor, and not just in Britain, but widely recognised as a leading voice for biological psychiatry that was listened to throughout the world.

In essence, he taught that one had to approach psychiatry not from a philosophical perspective, but in the manner of the scientist. Faced with the baffling complexity of mental illness phenomena, we must tease out the contributions of genes, of environment, of personality, of biochemistry. We must do so quantitatively, using the tools of mathematics, genetics, experimental biology and physics. These perceptions became enshrined not only in the standard treatments of psychiatry, but also in the definitions of the distinctive forms of mental illness captured in DSM (Diagnostic and Statistical Manual of the American Psychiatric Association) and ICD (International Classification of Diseases of the WHO), the drafting of which he was involved in from the beginning.

He emerged from these battles with his characteristic intellectual fearlessness, tenacity and honesty. These qualities were particularly needed when it came to dealing with the anti-psychiatry movement. He eventually published as a book a debate between himself and Thomas Szasz dealing with the question whether mental illness is merely a social construct. The proposition here was that there is no such thing as mental illness. Psychiatry merely provides a police and custodial service on behalf of the socio-political establishment to deal with deviancy. According to Szasz and Scientolo- gy, the whole psychiatric enterprise is bogus. According to Illich, we have no business medicalising the rich brocade of human diversity. Sir Martin's response to this came from his long experiences in the psychiatric hospitals, where one cannot escape from the reality and torment of mental illness, and where the post-modernist rhetoric becomes inaudible against the cries that echo along the corridors in the night. Mental illness is real illness: the problem is how to help.

He had a fine turn of phrase in these battles. I remember his advice when dealing with an opponent: "the rapier is better than the broadsword". Or when dealing with Derrida: "The tide of his rhetoric is unimpeded by the outcrops of fact lying in its path." Or on Illich: "a brooding presence in night, like a dysfunctional lighthouse, emitting shafts of darkness to confuse unwary travellers".

He had fierce battles also within psychiatry, the most renowned being with Kendell on the difference between Anxiety Disorder and Depression. Kendell argued that they form an undifferentiated spectrum of emotional disorder, too often seen together to be able to distinguish the two. Sir Martin argued that they were distinct biological entities, with different clinical features, different genetics and different natural history. Who was right in the end? From the diagnostic point of view, and also now from the molecular genetics, Sir Martin's concept has been enshrined in DSM and ICD. From a therapeutic point of view, there remains a large overlap in terms of treatment.

His real love and passion were for research. His earliest work was with Brain on psychological neglect of the half of the body affected by stroke, and from 1950, when he was appointed as Director of the Clinical Research Unit at the Graylingwell Hospital in Chichester, moved on to quantification of electroencephalographic phenomena and changes associated with electroconvulsive therapy. His research contributions came eventually to span the whole spectrum of psychiatry, superbly attested by a festschrift which appeared in 1989 on his retirement: "Contemporary Themes in Psychiatry: A Tribute to Sir Martin Roth.” We find here papers on classification in psychiatry, depression and anxiety, schizophrenia and above all the psychiatry of old age. When he was appointed to the Chair of Psychological Medicine in Newcastle in 1956 at the age of 39 he proceeded to establish what became one of the main centres of psychiatric clinical research in Britain, with particular strength in old age psychiatry.

Starting with the clinical rag-bag of "senile psychosis", undifferentiated forms of mental illness arising 
in late life, Sir Martin set about distinguishing the subtypes. He rescued Alois Alzheimer's original description of "Alzheimer's disease" from the clinical oblivion into which it had fallen, and elucidated the important distinctions between cerebrovascular dementia caused by strokes and Alzheimer's disease proper which is caused by abnormal protein formations in the brain. Working with his colleagues Tomlinson and Blessed, they devised the first scales for measuring dementia, and demonstrated the link between dementia and Alzheimer's abnormal proteins.

Sir Martin taught that it is only by bringing together the compassion and understanding of the medical mind, and the hard-edged clear light of clinical, biological and molecular science, that we can begin to understand the mysteries of mental illness, and more importantly devise new treatments. He carried this work forward when he became the first Professor of Psychiatry in Cambridge. Here he initiated a research project to understand the molecular structure of Alzheimer's abnormal protein formations, engaging the interest of Sir Aaron Klug who had just been awarded his Nobel Prize for Chemistry.

It was in 1981 that I first met Sir Martin, when he was at the pinnacle of his long and illustrious career, and I was a medical $\mathrm{PhD}$ student from Australia. He kindly welcomed me to Cambridge and to join the project on Alzheimer's disease. In the years since then I have had the opportunity to take towards practical fruition Sir Martin's intuition, that by understanding the structure of the abnormal proteins that cause Alzheimer's disease we might develop drugs to clear away the proteins and thereby cure Alzheimer's disease. The project later moved to Aberdeen University and led to a spin-out company, TauRx Therapeutics, which is completing a large clinical trial of the first ever treatment aimed at dissolving Alzheimer's tangle. Early next year, when the data is unblinded, we will finally learn whether Sir Martin's fundamental intuition was right.

The enduring sadness of the biological revolution in psychiatry that Sir Martin helped to inspire is that its early promise has not been fulfilled through new treatments. Kraepelin delineated the major disorders, schizophrenia and manic depressive disorder in the 1890's. Although there are newer drugs that do much the same as the originals of the 1960's, no fundamentally new approaches have emerged. This is not for want of effort, as neuroscience research is now a vast worldwide enterprise. The problem is that these disorders have proved to be difficult to unravel, and unlike Alzheimer's disease, the mechanism of these diseases leaves no discernible trace in the brain. Unravelling them may take several more generations of research.

Future generations of psychiatrist-scientists, alas, will not now have as wise and insightful a guide as Sir Martin. He delighted when the research data seemed to present an impossible paradox: he would say that a paradox is already progress, because it presents an opportunity for resolution which simply awaits our ingenuity. Sadly, there are fewer psychiatrist-scientists now, and neither the training programs, nor the National Health Service in the UK, nor the trainees themselves seem to understand that it is their duty, their opportunity and their privilege to confront head-on the diseases which cause so much human misery.

As the last of Sir Martin's pupils, the last of the "Roth-mafia" of professors of psychiatry he trained and inspired, I particularly miss him. All who worked with him will miss his unique blend of profound medical compassion for suffering humanity, along with his mental toughness, intellectual rigour and brilliance, and fundamental strength of character. I often find myself wishing he were still here to guide us, often thinking, when dealing with a difficult situation, how would Sir Martin have dealt with this?

Sir Martin leaves behind him a loving family. His wife, Lady Constance Roth, a graduate of the London School of Economics, was a tireless support and a discerning and intelligent companion. He also leaves three daughters and nine grandchildren. But above all, Sir Martin leaves behind him a real and lasting contribution to humanity in his time, and an indelible mark on the landscape of psychiatry.

Claude M. Wischik

Professor of Psychiatric Geratology, \& Chairman of TauRx Therapeutics, University of Aberdeen, UK 